TITLE: Waist circumference centiles for UK South Asian children

Corresponding author: Dr Mahjabeen Shah

Current work address: Kingston University, School of Life Sciences, Pharmacy and Chemistry Faculty of Science, Engineering and Computing, Penrhyn Road, Kingston upon Thames, KT1 $2 \mathrm{EE}$

Home address: 11 Denmark Rd, Kingston upon Thames, KT1 2SD

Email: Mahjabeen.shah@kingston.ac.uk

Tel: 07425-150419

\title{
Co-authors:
}

1. Dr Dimple Radia, London Metropolitan University, London, England, UK.

2. Professor H. David McCarthy, London Metropolitan University, London, England, UK.

Key words: Obesity, abdominal fat, waist circumference, child, centiles

Word count: 2355 


\section{Waist circumference centiles for UK South Asian children}

\section{Abstract}

Objectives: To develop waist circumference (WC) centile curves for UK South Asian children. To make comparisons with published centiles for British, indigenous Indian and Pakistani children, as well as to make anthropometric comparisons with their UK white peers.

Design: Cross-sectional study

Setting: School-aged children from London boroughs (main measures: 2004-2007).

Participants: 1562 (652 boys, 910 girls) UK South Asian and 1,120 (588 boys, 532 girls) UK white children aged $4.0-13.9 y$.

Interventions: WC, height, weight and BMI

Main outcome measures: Smoothed WC centile curves, constructed using the LMS method. Standard deviation scores (SDS) were generated using UK90 and British (WC) growth reference data.

Results: WC increased with age for both sexes, rising more steeply at the upper centiles after age 6y. Overall, UK South Asian children, similar to indigenous South Asian populations, had higher WC values than the reference British children (25). However, compared to their UK white peers, UK South Asian children had significantly $(p<0.001)$ lower mean WC (UK white SDS $=0.74$ and 0.64 vs UK South Asian 0.32 and 0.21 for boys and girls respectively).

Obesity prevalence was greater using WC than BMI for both ethnicities. At the $90^{\text {th }}$ centile (International Diabetes Federation WC cut-off for abdominal obesity), for UK South Asian 
children, prevalence was $21.5 \%$ vs $24.4 \%$ for boys and $17 \%$ vs $24.5 \%$ for girls based on BMI and WC respectively.

Conclusions: These curves represent the first WC centiles for UK South Asian children up to age $14 y$. With a continued rise in childhood obesity, they provide a useful historical control for future comparisons. 


\section{Introduction}

Waist circumference (WC) is a simple, predictive measure of abdominal adiposity (1). Over the last 20y within the UK, WC has increased more steeply than body mass index (BMI) among children and adolescents (2). BMI cannot differentiate between lean tissue and body fat, or provide an indication of body fat distribution, whereas an excess accumulation of abdominal fat is associated with an increased metabolic risk (3-7). In children and adolescents, compared to $\mathrm{BMI}, \mathrm{WC}$ is more strongly associated with components of metabolic disease, including an adverse atherogenic lipoprotein profile (3), raised fasting insulin concentration (5), elevated blood pressure (6) and non-alcoholic fatty liver disease(7).

South Asians have a greater risk of type 2 diabetes mellitus (T2DM) and cardiovascular disease (CVD) than white Europeans (8). This increased risk is linked, in part, to South Asians having a genetic propensity to insulin resistance, attributed to greater total body fatness, increased abdominal obesity (9), and less skeletal muscle mass (SMM) $(10,11)$ than white Europeans, at any given BMI (12,13). These ethnic differences are present from birth (14), and throughout childhood and adolescence $(11,15,16)$, with South Asian children <16y almost 14 times at greater risk of developing symptoms of metabolic disease than their white European peers (17). Consequently, a downward revision of overweight and obese BMI cut-offs referred to as 'public health action points' for South Asian adults has been proposed by the World Health Organisation (WHO) (12). In addition, the International Diabetes Federation (IDF) has recommended a lower WC cut-off to define abdominal obesity for South Asians (18).

Across childhood and adolescence, centile charts are used to classify overweight and obesity, with the $85^{\text {th }}$ and $95^{\text {th }}$ centiles for $\mathrm{BMI}$ representing overweight and obese cut-offs 
respectively (19) for population monitoring (20) and $91^{\text {st }}$ centile and $98^{\text {th }}$ centiles for clinical assessment (21). Lowered BMI cut-offs that pass through the South Asian adult cut-offs for overweight (BMI $23 \mathrm{~kg} / \mathrm{m}^{2}$ ) and obesity (BMI $27.5 \mathrm{~kg} / \mathrm{m}^{2}$ ) at age 18y (12) have also been proposed for Indian children (22). More recently, ethnic-specific adjustment of BMI for UK South Asian children across all ages has been proposed, to account for the underestimation of body fat by BMI in this population (23).

The IDF recommends use of $\geq 90^{\text {th }}$ centile WC cut-off for determining central obesity in children aged $6-<10 y(24)$. In children and adolescents aged $10-<16 y$, in addition to two or more clinical measures (e.g. blood pressure or fasting lipids), the IDF recommends this WC cut-off (or the adult cut-off if lower), ideally using ethnic-specific WC centile charts where available, for diagnosing metabolic disease. Several ethnic-specific WC centile charts have been developed worldwide, including Great Britain (25) , USA (26), India (27) and Pakistan (28). The British WC centile curves (25), were based predominantly on a sample of white children and adolescents aged 5.0-16.9y. However, equivalent centile curves for UK South Asian children are currently unavailable. Therefore, the aims of this study were to: i) develop WC centiles for UK South Asian children aged 4-13.9y; ii) compare these with the British WC centile reference curves, and those developed for indigenous Indian and Pakistani populations; iii) make comparisons with their UK white peers from similar socioeconomic backgrounds, for WC and other anthropometric measures. 


\section{Methods}

\section{Participants}

Data from a previous school-based study collected between 2004 and 2007 were used (29). This dataset contained anthropometric measures of a large South Asian cohort of 1,459 UK children (584 boys, 875 girls) and 1,120 UK white children (588 boys, 532 girls) aged 4.00$13.9 y$, recruited from primary and secondary schools from inner-city and Greater London boroughs, reflecting the variation in the socioeconomic background of the participants. As the number of children of a Pakistani origin was lower than children from Indian and Bangladeshi backgrounds, an additional cross-sectional sample of 103 children ( 68 boys, 35 girls) aged 4.00-13.9y, were recruited from mosques and Muslim community centres from Greater London, between 2010 and 2012.

Ethical approval was obtained from London Metropolitan University's Ethics Committee. Consent forms, letters of invitation, and information packs were distributed to interested participants, with signed parental consent, together with child assent, required for participation in this study. Gender, date of birth and ethnicity were provided by the schools, with ethnicity defined using the Department for Children, Schools and Family classification system (30).

\section{Measures}

Trained observers took all measures of WC and height respectively to the nearest $0.1 \mathrm{~cm}$ following standard procedures (31). WC was measured using a Seca flexible non-elastic, retractable tape measure, over a single layer of clothing, approximately midway between the top of the iliac crest and lower border of the bottom rib; $0.5 \mathrm{~cm}$ was deducted from the 
measurement to account for clothing (2). Height was measured using a portable stadiometer (Leicester Height Measure (LHM)), in bare feet with head adjusted to the Frankfort plane position (31). Body weight was measured to the nearest $0.1 \mathrm{~kg}$, in light indoor clothing with bare feet (with $0.5 \mathrm{~kg}$ subtracted to account for clothing), using a Tanita BC418-MA (Tokyo, Japan) Bioelectrical Impedance Analyser (BIA), which incorporates an electronic digital scale. BMI was calculated as weight $(\mathrm{kg}) /$ height $\left(\mathrm{m}^{2}\right)$.

\section{Statistical analyses}

Data were analysed using Microsoft Excel (2011) and SPSS version 22 (SPSS Inc. Chicago IL, USA). Decimal age was calculated by the formula: (date of measurement - date of birth)/365.25. Data are presented as mean (SD).

Gender and age-specific standard deviation scores (SDS) were generated in Excel, for all anthropometric variables using the Microsoft Excel add-on LMSgrowth, which contains the UK90 (19) and the British WC (25) growth reference data. Gender and age-specific smoothed waist circumference centiles were constructed using the Cole and Green method, employed in the software LMSchartmaker Light (http://www.healthforallchildren.com/Ims-chartmakerlight-download/) (32). For BMI, children were classified as overweight or obese at the $85^{\text {th }}$ (SDS 1.04) and $95^{\text {th }}$ (SDS 1.64) centile cut-offs respectively, using the UK90 BMI reference data (19). 
WC comparisons between the UK South Asian sample and British references (25) at the $50^{\text {th }}$ and $90^{\text {th }}$ centiles were performed. Detailed between group comparisons were made between the UK South Asians and their UK white peers for all anthropometric measures (SDS format), using independent samples t-tests. Statistical significance was set at $\mathrm{P}<0.05$. Comparisons of obesity prevalence between BMI (19) and WC (25) were made at the $95^{\text {th }}$ (BMI obesity cutoff) and $90^{\text {th }}$ (IDF WC cut-off) centiles for both UK South Asian and UK white children.

\section{Results}

The final sample size comprised 1562 (41.7\% boys and 58.3\% girls) UK South Asian children aged $4.0-13.9 y$. The mean and SD values of all measured variables for the Pakistani subsample were very similar to the main data-set (data not shown). Table 1 shows sex-specific descriptive characteristics (absolute and SDS) for weight, height, BMI and WC by age. Table 2 shows the sample size and selected WC centile values by age and sex.

Figure 1 shows the smoothed WC centile curves for UK South Asian boys and girls respectively, equivalent to the format of the UK90 BMI reference curves, which employs the convention of 9 centiles with a two-thirds SD score spacing (19). For both sexes, WC increased with age and extreme skewness was observed, with the lower centiles much closer together than the upper centiles. This skewness was reflected in the L-values were more extreme than UK90, (19) ranging from -3 to -1 , and -4 to -2 for girls and boys respectively. Sex-specific comparisons at the $50^{\text {th }}$ and $90^{\text {th }}$ WC centiles with the equivalent British (25), indigenous Indian (27), and Pakistani (28) centiles, are shown in Figure $2 \mathrm{a}$ and $2 \mathrm{~b}$. At the $50^{\text {th }}$ centile, for both sexes, the curves were similar for UK South Asian and British children, up to age 8y, after which UK South Asian centiles were consistently higher. For boys, the indigenous Indian and Pakistani curves were very similar to the UK South Asian curves at the $50^{\text {th }}$ centile, particularly from age $8 \mathrm{y}$ 
onwards, where the curves overlapped. For UK South Asian girls, the greatest differences between the British girls appeared from age 11-12y onwards.

At the 90th centile, from age 6y onwards, higher WC values were apparent in both sexes for UK South Asian and indigenous South Asian groups compared with British centiles. From age 8 years Indian boys had consistently lower WC values compared with the other groups. For girls, UK South Asian WC values were consistently lower than Indian and Pakistani groups.

Table 3 shows anthropometric SDS for the UK South Asian and UK white children. Compared with the references $(19,25)$, UK South Asians were very similar to the mean for height and weight, with a slightly lower BMI, but higher WC. However, compared with their UK white peers, UK South Asians were significantly shorter, lighter, with a lower BMI and WC $(P<0.001)$. At the $95^{\text {th }}$ (obese BMI) and $90^{\text {th }}$ centile (raised WC) cut-offs, prevalence of obesity (Table 3 ) was lower in UK South Asians than in the UK white cohort for both sexes. However, compared to BMI, a greater proportion of both UK white and UK South Asian children were identified at or above the $95^{\text {th }}$ and $90^{\text {th }}$ centiles for WC. 


\section{Discussion}

This study presents the first set of sex-specific WC centiles for UK South Asian children aged 4-13.9y. WC increased with age, with the median value consistently higher in boys, as found in other studies using similar measurement techniques $(25,27,28)$. This highlights the importance of standardised measurement procedures, necessary for making reliable comparisons.

Similar to indigenous South Asian children $(27,28)$, UK South Asian children had a higher WC than the British children (25), this being more marked at the $90^{\text {th }}$ centile, with greater differences observed in older children (7-8y). The extreme skewness of the centiles (Figure 1), with a much steeper increase in the upper centiles ( $>75^{\text {th }}$ centile), particularly for boys, from age $6 y$ upwards, suggests increasing abdominal adiposity among school-aged children. This pattern reflects the more current obesity prevalence data, with higher levels of obesity reported in children aged 10-11y than younger children (33), together with the rise in obesity over the last few decades (34). This trend in obesity is evident in the comparisons between the UK South Asians and the UK white sample, where UK South Asian children had significantly lower BMI and WC as well as other anthropometric measures than their UK white peers. This finding has also been observed in other studies comparing contemporary white European and South Asian children $(4,11)$. A lower WC may suggest a lower level of abdominal obesity among South Asian children. However, it is important to note that compared to the UK90 reference data (19), UK South Asian children on average, had similar BMI but higher WC measures. In another study, despite BMI and WC measures being lower among the South Asian children compared to the white European cohort, overall levels of adiposity were higher as judged by higher trunk skinfold measures (11).

Higher levels of obesity prevalence were identified based on WC than BMI centile cut-offs for both UK white and UK South Asian children, which has been observed elsewhere (27). This demonstrates that using only BMI for determining obesity among South Asian children, may underestimate the 
proportion at risk of obesity-related morbidity. This could be identified by using an appropriate WC cut-off, such as the IDF $90^{\text {th }}$ centile cut-off or lower (18).

Lowering the WC thresholds for abdominal obesity for South Asian children is supported by evidence of a 'thin-fat' phenotype present from birth (14), with greater cardiometabolic risk factors present at lower WC and BMI centiles than white European and other populations $(10,11,13)$. The difficulty with prescribing specific centile values for determining overweight and obese thresholds, is that unlike adult cut-offs which are fixed values, rising levels of obesity over the past few decades has resulted in an upward shift in WC at any given centile value. Hence, the use of lower South Asian adult-cut offs to extrapolate appropriate centile values, as has been proposed for BMI centiles for Indian children (22), or an adjustment in BMI to account for the higher BF to BMI relationship proposed for South Asian children (23), would seem prudent options to follow for South Asian WC centiles. Moreover, due to the secular increase in obesity, the $75^{\text {th }}$ centile has been proposed as an 'action point' for identifying obesity in Indian children aged 3-16y (27). However, for UK South Asian children, the $75^{\text {th }}$ centile might be considered inappropriate. One way forward may be to develop WC centile cut-offs which pass through the adult South Asian WC cut-offs at age 18y, similar to the International Obesity Task Force BMI curves (35). However, further research is required to supplement this data set for children $14-18 y$, to enable extrapolation to adult values. Additionally, it would be important to follow the IDF (24) recommendation that WC cut-offs for abdominal obesity and diagnosing metabolic syndrome for children aged $10-<16 y$, should also include clinical measures.

\section{Limitations}

The South Asian dataset contained considerably more girls than boys, due to one of the schools being an all-girls school. However, most age groups contained over 50 participants, apart from boys 
aged 12-12.9y ( $n=49)$, and under 30 participants aged 4-4.9y, for both sexes. Additionally, the age range only extended to $14 y$, due to participating schools limiting access to older year groups.

\section{Conclusion}

In conclusion, this study provides the first set of WC centile curves for UK South Asian children. WC better predicts adiposity-associated health risks than BMI, particularly for South Asian populations with greater abdominal fat from early childhood. Lower WC cut-offs could be adopted for UK South Asian children in line with adult cut-offs, for determining abdominal obesity. These charts could be used clinically and in population surveys, for tracking changes in abdominal adiposity to promote preventative action.

\section{Competing interests: None declared}

Funding Statement: This research received no specific grant from any funding agency in the public, commercial or not-for-profit sectors.

Contributorship Statement: MS was the main author, who conducted this study. HDM conceived and designed the study assisted with the analysis and interpretation of the data and with writing the manuscript. D R was involved in the field work and collection of the data. 


\section{What is already known on this topic}

1. South Asians are a high-risk population for cardiometabolic disease which tracks from childhood into adulthood, attributed in part, to the South Asian thin-fat phenotype.

2. Lower BMI and waist circumference (WC) cut-offs for overweight and obesity are recommended for South Asian adults in recognition of this risk.

3. WC is accepted as an indicator of abdominal obesity, and ethnic-specific WC centiles have been developed for children in many countries worldwide.

\section{What this study adds}

1. The first WC centile charts for UK South Asian children aged 4-13.9 y.

2. Confirmation that more children are identified as obese when based on WC than BMI.

3. These charts can be used clinically and in epidemiological settings, as a marker of abdominal adiposity in UK South Asian children, which together with other clinical markers could be used in lifestyle interventions as a means of preventing adiposity related diseases. 


\section{References}

(1) McCarthy HD. Measuring growth and obesity across childhood and adolescence. Proc Nutr Soc 2014;73(2):210217.

(2) McCarthy HD, Ellis SM, Cole TJ. Central overweight and obesity in British youth aged 11-16 years: cross sectional surveys of waist circumference. BMJ 2003 Mar 22;326(7390):624.

(3) Flodmark CE, Sveger T, Nilsson-Ehle P. Waist measurement correlates to a potentially atherogenic lipoprotein profile in obese 12-14-year-old children. Acta Paediatr 1994 Sep;83(9):941-945.

(4) Shen W, Punyanitya M, Chen J, Gallagher D, Albu J, Pi-Sunyer X, et al. Waist circumference correlates with metabolic syndrome indicators better than percentage fat. Obesity (Silver Spring) 2006 Apr;14(4):727-736.

(5) Freedman DS, Serdula MK, Srinivasan SR, Berenson GS. Relation of circumferences and skinfold thicknesses to lipid and insulin concentrations in children and adolescents: the Bogalusa Heart Study. Am J Clin Nutr 1999 Feb;69(2):308317.

(6) Choy CS, Chan WY, Chen TL, Shih CC, Wu LC, Liao CC. Waist circumference and risk of elevated blood pressure in children: a cross-sectional study. BMC Public Health 2011 Aug 2;11:613.

(7) Manco M, Bedogni G, Marcellini M, Devito R, Ciampalini P, Sartorelli MR, et al. Waist circumference correlates with liver fibrosis in children with non-alcoholic steatohepatitis. Gut 2008 Sep;57(9):1283-1287.

(8) Gholap N, Davies M, Patel K, Sattar N, Khunti K. Type 2 diabetes and cardiovascular disease in South Asians. Prim Care Diabetes 2011 Apr;5(1):45-56.

(9) Luke A. Ethnicity and the BMI-body fat relationship. Br J Nutr 2009;102(04):485-487.

(10) Lear SA, Kohli S, Bondy GP, Tchernof A, Sniderman AD. Ethnic variation in fat and lean body mass and the association with insulin resistance. J Clin Endocrinol Metab 2009 Dec;94(12):4696-4702.

(11) Nightingale CM, Rudnicka AR, Owen CG, Cook DG, Whincup PH. Patterns of body size and adiposity among UK children of South Asian, black African-Caribbean and white European origin: Child Heart And health Study in England (CHASE Study). Int J Epidemiol 2010;40(1):33-44.

(12) WHO Expert Consultation. Appropriate body-mass index for Asian populations and its implications for policy and intervention strategies. Lancet 2004 Jan 10;363(9403):157-163.

(13) Bodicoat DH, Gray LJ, Henson J, Webb D, Guru A, Misra A, et al. Body mass index and waist circumference cutpoints in multi-ethnic populations from the UK and India: the ADDITION-Leicester, Jaipur heart watch and New Delhi cross-sectional studies. PloS one 2014;9(3):e90813.

(14) Yajnik CS, Lubree HG, Rege SS, Naik SS, Deshpande JA, Deshpande SS, et al. Adiposity and hyperinsulinemia in Indians are present at birth. J Clin Endocrinol Metab 2002 Dec;87(12):5575-5580.

(15) Schwandt P, Bertsch T, Haas GM. Anthropometric screening for silent cardiovascular risk factors in adolescents: The PEP Family Heart Study. Atherosclerosis 2010 Aug;211(2):667-671.

(16) Bhardwaj S, Misra A, Khurana L, Gulati S, Shah P, Vikram NK. Childhood obesity in Asian Indians: a burgeoning cause of insulin resistance, diabetes and sub-clinical inflammation. Asia Pac J Clin Nutr 2008;17 Suppl 1:172-175.

(17) Whincup PH, Nightingale CM, Owen CG, Rudnicka AR, Gibb I, McKay CM, et al. Early emergence of ethnic differences in type 2 diabetes precursors in the UK: the Child Heart and Health Study in England (CHASE Study). PLoS Med 2010 Apr 20;7(4):e1000263. 
(18) Alberti, Kurt George Matthew Mayer, Zimmet P, Shaw J. International Diabetes Federation: a consensus on Type 2 diabetes prevention. Diabetic Med 2007;24(5):451-463.

(19) Cole TJ, Freeman JV, Preece MA. Body mass index reference curves for the UK, 1990. Arch Dis Child 1995 Jul;73(1):25-29.

(20) Barlow SE, Expert Committee. Expert committee recommendations regarding the prevention, assessment, and treatment of child and adolescent overweight and obesity: summary report. Pediatrics 2007 Dec;120 Suppl 4:164.

(21) National Institute for Health and Care Excellence. Identification, assessment and management of overweight and obesity in children, young people and adults (Clinical Guideline 189). 2014; Available at: www.nice.org.uk/guidance/cg189. Accessed 05/23, 2017.

(22) Khadilkar VV, Khadilkar AV, Borade AB, Chiplonkar SA. Body mass index cut-offs for screening for childhood overweight and obesity in Indian children. Indian Pediatr 2012;49(1):29-34.

(23) Hudda MT, Nightingale CM, Donin AS, Fewtrell MS, Haroun D, Lum S, et al. Body mass index adjustments to increase the validity of body fatness assessment in UK Black African and South Asian children. Int J Obes (Lond) 2017 Apr 25.

(24) Alberti G, Zimmet P, Kaufman F, Tajima N, Silink M, Arslanian S, et al. The IDF consensus definition of the metabolic syndrome in children and adolescents. Pediatric Diabetes 2007;8(5):299-306.

(25) McCarthy HD, Jarrett KV, Crawley HF. The development of waist circumference percentiles in British children aged 5.0-16.9 y. Eur J Clin Nutr 2001 Oct;55(10):902-907.

(26) Fernandez JR, Redden DT, Pietrobelli A, Allison DB. Waist circumference percentiles in nationally representative samples of African-American, European-American, and Mexican-American children and adolescents. J Pediatr 2004 Oct;145(4):439-444.

(27) Kuriyan R, Thomas T, Lokesh DP, Sheth NR, Mahendra A, Joy R, et al. Waist circumference and waist for height percentiles in urban South Indian children aged 3-16 years. Indian Pediatr 2011 Oct;48(10):765-771.

(28) Mushtaq MU, Gull S, Abdullah HM, Shahid U, Shad MA, Akram J. Waist circumference, waist-hip ratio and waistheight ratio percentiles and central obesity among Pakistani children aged five to twelve years. BMC Pediatr 2011 Nov 21;11:105.

(29) Samani-Radia D, McCarthy HD. Comparison of children's body fatness between two contrasting income groups: contribution of height difference. Int J Obes (Lond) 2011 Jan;35(1):128-133.

(30) Department for Children, Schools and Families. No title. Available at: http://www.dcsf.gov.uk/foischeme/subpage.cfm?action=collections.displaycollection\&i collectionID=157. Accessed 10/19, 2009.

(31) World Health Organization. Physical status: The use of and interpretation of anthropometry, Report of a WHO Expert Committee. 1995.

(32) Cole TJ, Green PJ. Smoothing reference centile curves: the LMS method and penalized likelihood. Stat Med 1992;11(10):1305-1319.

(33) Gatineau M MS. Obesity and ethnicity. 2011; Available at: http://www.noo.org.uk/NOO pub/briefing papers. Accessed 02/06, 2012.

(34) Wardle J, Brodersen NH, Cole TJ, Jarvis MJ, Boniface DR. Development of adiposity in adolescence: five year longitudinal study of an ethnically and socioeconomically diverse sample of young people in Britain. BMJ 2006 May 13;332(7550):1130-1135. 
(35) Cole TJ and Lobstein T. Extended international (IOTF) body mass index cut-offs for thinness, overweight and obesity. Pediatr Obes 2012 Aug;7(4):284-294. 
Table 1 Mean (SD) absolute and SDS for Weight, Height, BMI, and waist circumference data of UK SA children aged 4.0-13.9 years ( $n=1562$ )

\begin{tabular}{|c|c|c|c|c|c|c|c|c|c|}
\hline Age (years) & $n$ & Weight (kg) & Height $(\mathrm{cm})$ & BMI $\left(\mathrm{kg} / \mathrm{m}^{2}\right)$ & $\begin{array}{l}\text { Waist } \\
\text { circumference } \\
\text { (cm) }\end{array}$ & Weight SDS & Height SDS & BMI SDS & $\begin{array}{l}\text { Waist } \\
\text { circumference } \\
\text { SDS }\end{array}$ \\
\hline \multicolumn{10}{|c|}{ Boys $(n=652)$} \\
\hline $4+$ & 22 & $17.8(0.2)$ & $107.2(4.9)$ & $15.3(2.4)$ & $50.3(5.5)$ & $-0.4(1.5)$ & $-0.1(1.1)$ & $-0.5(1.5)$ & $-0.6(1.4)$ \\
\hline $5+$ & 74 & $18.7(2.5)$ & $111.6(4.3)$ & $14.9(1.4)$ & $51.7(3.9)$ & $-0.5(1.1)$ & $-0.2(0.9)$ & $-0.7(1.2)$ & $-0.2(1.1)$ \\
\hline $6+$ & 89 & $21.6(4.1)$ & $118.5(5.3)$ & $15.2(2.1)$ & $53.4(5.0)$ & $-0.4(1.4)$ & $-0.1(1.0)$ & $-0.5(1.5)$ & $-0.0(1.3)$ \\
\hline $7+$ & 82 & $24.5(5.2)$ & $124.2(6.2)$ & $15.8(2.3)$ & $55.6(6.0)$ & $-0.2(1.4)$ & $-0.1(0.9)$ & $-0.2(1.5)$ & $0.2(1.3)$ \\
\hline $8+$ & 69 & $27.9(6.9)$ & $129.6(6.9)$ & $16.4(2.8)$ & $58.4(7.4)$ & $-0.2(1.6)$ & $-0.1(1.2)$ & $-0.1(1.6)$ & $0.4(1.4)$ \\
\hline $9+$ & 67 & $31.4(9.0)$ & $134.3(6.4)$ & $17.2(3.7)$ & $61.4(9.5)$ & $-0.0(1.3)$ & $-0.2(1.1)$ & $0.1(1.5)$ & $0.6(1.3)$ \\
\hline $10+$ & 81 & $37.8(11.3)$ & $140.9(6.4)$ & $18.7(4.4)$ & $66.3(11.5)$ & $0.4(1.5)$ & $0.1(0.9)$ & $0.4(1.7)$ & $0.8(1.5)$ \\
\hline $11+$ & 65 & $39.2(9.4)$ & $145.1(6.0)$ & 18.5 (3.8) & $66.9(10.2)$ & $0.2(1.2)$ & $-0.1(0.9)$ & $0.2(1.6)$ & $0.6(1.3)$ \\
\hline $12+$ & 49 & 45.7 (11.9) & $154.0(9.6)$ & $18.8(3.4)$ & $67.7(8.7)$ & $0.3(1.3)$ & $0.4(1.1)$ & $0.1(1.4)$ & $0.5(1.1)$ \\
\hline $13+$ & 54 & 48.9 (12.1) & $160.2(8.1)$ & $18.9(3.7)$ & $68.0(10.2)$ & $0.2(1.3)$ & $0.3(1.0)$ & $-0.1(1.5)$ & $0.2(1.3)$ \\
\hline \multicolumn{10}{|c|}{ Girls $(n=910)$} \\
\hline $4+$ & 27 & $16.1(3.8)$ & $104.9(4.9)$ & $14.4(2.3)$ & $48.2(4.9)$ & $-1.0(1.6)$ & $-0.3(1.0)$ & $-1.2(2.4)$ & $-0.9(1.5)$ \\
\hline $5+$ & 66 & $18.0(2.4)$ & $110.7(4.8)$ & $14.6(1.4)$ & $50.3(3.6)$ & $-0.7(1.0)$ & $-0.3(1.0)$ & $-0.7(1.0)$ & $-0.4(1.0)$ \\
\hline $6+$ & 69 & $20.8(4.5)$ & $117.6(6.0)$ & $15.0(2.4)$ & $52.6(5.9)$ & $-0.5(1.3)$ & $-0.2(1.2)$ & $-0.6(1.5)$ & $-0.1(1.4)$ \\
\hline $7+$ & 87 & $24.2(5.3)$ & $123.1(6.2)$ & $15.7(2.3)$ & $54.7(5.7)$ & $-0.2(1.3)$ & $-0.1(1.1)$ & $-0.3(1.2)$ & $0.1(1.2)$ \\
\hline $8+$ & 73 & $27.0(6.1)$ & $128.1(5.4)$ & $16.2(2.8)$ & $56.4(6.4)$ & $-0.3(1.3)$ & $-0.3(1.0)$ & $-0.3(1.3)$ & $0.1(1.3)$ \\
\hline $9+$ & 68 & 31.1 (7.3) & $135.9(8.0)$ & $16.6(2.8)$ & $58.7(7.4)$ & $-0.2(1.3)$ & $0.1(1.3)$ & $-0.3(1.2)$ & $0.3(1.3)$ \\
\hline $10+$ & 63 & $33.0(7.3)$ & $139.4(6.0)$ & $16.8(2.9)$ & $59.3(8.0)$ & $-0.4(1.2)$ & $-0.2(1.0)$ & $-0.5(1.4)$ & $0.1(1.5)$ \\
\hline $11+$ & 206 & $41.3(11.8)$ & $147.2(7.7)$ & $18.8(4.2)$ & $63.4(10.2)$ & $0.1(1.4)$ & $0.1(1.0)$ & $0.0(1.5)$ & $0.4(1.6)$ \\
\hline $12+$ & 190 & $46.6(10.5)$ & $152.5(6.5)$ & $19.8(4.0)$ & $66.1(9.7)$ & $0.2(1.3)$ & $0.0(0.9)$ & $0.2(1.5)$ & $0.6(1.6)$ \\
\hline $13+$ & 61 & 45.5 (7.9) & $155.6(5.6)$ & $18.8(3.2)$ & $63.6(7.0)$ & $-0.3(1.0)$ & $-0.2(0.9)$ & $-0.3(1.3)$ & $0.0(1.4)$ \\
\hline
\end{tabular}

SDS = standard deviation scores (generated from UK90 LMSgrowth (19) and British WC (25) reference data); UK SA = South Asian (of Indian, Pakistani, and Bangladeshi descent); BMI = body mass index 
Table 2 Smoothed waist circumference $(\mathrm{cm})$ centiles by age and sex for UK South Asian children

\section{Centiles}

\begin{tabular}{|c|c|c|c|c|c|c|c|c|c|c|c|}
\hline Sex & $\begin{array}{l}\text { Age } \\
\text { (years) }\end{array}$ & $n$ & $2^{\text {nd }}$ & 9th & 25th & 50th & 75th & 90th & 91st & 98th & 99.6th \\
\hline \multirow[t]{11}{*}{ Boys } & 4 & 22 & 44.3 & 45.6 & 47.0 & 48.6 & 50.7 & 53.1 & 53.3 & 57.3 & 62.4 \\
\hline & 5 & 74 & 45.0 & 46.4 & 48.0 & 50.0 & 52.5 & 55.4 & 55.7 & 60.7 & 67.6 \\
\hline & 6 & 89 & 45.7 & 47.4 & 49.4 & 51.8 & 54.9 & 58.6 & 59.0 & 65.6 & 75.6 \\
\hline & 7 & 82 & 46.5 & 48.5 & 50.8 & 53.7 & 57.4 & 62.0 & 62.5 & 71.0 & 84.3 \\
\hline & 8 & 69 & 47.5 & 49.8 & 52.5 & 55.9 & 60.4 & 65.9 & 66.5 & 77.0 & 94.1 \\
\hline & 9 & 67 & 48.7 & 51.4 & 54.5 & 58.4 & 63.6 & 70.1 & 70.8 & 83.5 & 104.9 \\
\hline & 10 & 81 & 50.1 & 53.1 & 56.5 & 60.9 & 66.8 & 74.2 & 75.1 & 89.7 & 115.1 \\
\hline & 11 & 65 & 51.4 & 54.6 & 58.4 & 63.2 & 69.6 & 77.8 & 78.7 & 94.8 & 122.2 \\
\hline & 12 & 49 & 52.6 & 56.1 & 60.1 & 65.3 & 72.2 & 80.8 & 81.8 & 98.8 & 126.9 \\
\hline & 13 & 54 & 53.8 & 57.5 & 61.8 & 67.2 & 74.5 & 83.5 & 84.6 & 102.1 & 130.4 \\
\hline & & & 2nd & 9th & 25th & 50th & 75th & 90th & 91st & 98th & 99.6th \\
\hline \multirow[t]{10}{*}{ Girls } & 4 & 27 & 41.6 & 43.1 & 44.8 & 46.8 & 48.8 & 52.0 & 52.3 & 56.7 & 62.1 \\
\hline & 5 & 66 & 42.7 & 44.4 & 46.3 & 48.5 & 50.8 & 54.5 & 54.8 & 60.1 & 66.6 \\
\hline & 6 & 69 & 44.1 & 46.0 & 48.1 & 50.7 & 53.3 & 57.7 & 58.1 & 64.4 & 72.6 \\
\hline & 7 & 87 & 45.3 & 47.4 & 49.8 & 52.8 & 55.7 & 60.8 & 61.3 & 68.9 & 79.0 \\
\hline & 8 & 73 & 46.3 & 48.6 & 51.3 & 54.6 & 58.0 & 63.8 & 64.4 & 73.1 & 84.9 \\
\hline & 9 & 68 & 47.0 & 49.6 & 52.6 & 56.3 & 60.1 & 66.6 & 67.2 & 77.0 & 90.2 \\
\hline & 10 & 63 & 47.7 & 50.6 & 53.9 & 58.0 & 62.2 & 69.5 & 70.2 & 80.8 & 94.9 \\
\hline & 11 & 206 & 48.6 & 51.9 & 55.5 & 60.1 & 64.7 & 72.7 & 73.3 & 84.7 & 99.2 \\
\hline & 12 & 190 & 49.9 & 53.5 & 57.5 & 62.0 & 67.4 & 76.0 & 76.7 & 88.5 & 103.1 \\
\hline & 13 & 61 & 50.9 & 54.8 & 59.1 & 64.4 & 69.7 & 78.5 & 79.3 & 91.2 & 105.1 \\
\hline
\end{tabular}

Age presented as exact ages; UK South Asian (of Indian, Pakistani, and Bangladeshi descent) 
Figure 1 Sex-specific smoothed waist circumference centile curves with 9 centiles spaced two thirds of an SD score apart (19), for UK children of South Asian (Indian, Pakistani, and Bangladeshi) descent aged 4.0-13.9y

Figure 2 Sex-specific comparisons of smoothed centiles for waist circumference between UK SA, British (25), Pakistani (28) and Indian (27) children aged 5-13.9y (where available). WC = Waist circumference; UK SA = UK South Asian (of Indian, Pakistani, and Bangladeshi descent). 
Table 3 Mean SDS (SD) sex-specific comparisons of UK South Asian and UK white cohorts for height, weight, BMI, waist circumference, with prevalence comparisons ( $\mathrm{n}(\%)$ ) of obese BMI \& WC SDS at the $95^{\text {th }} \& 90$ th centiles

\begin{tabular}{lllll}
\multicolumn{3}{c}{ Boys } & \multicolumn{3}{c}{ Girls } \\
\hline & UK SA & UK white & UK SA & UK white \\
& $(n=652)$ & $(n=588)$ & $(n=910)$ & $(n=532)$ \\
Age (y) & $9.2(2.8)$ & $8.8(2.5)$ & $10.1(2.6)$ & $8.8(2.4)$ \\
Height SDS & $-0.0^{*}(1.0)$ & $0.30(1.0)$ & $-0.1^{*}(1.0)$ & $0.2(1.0)$ \\
Weight SDS & $-0.1^{*}(1.4)$ & $0.4(1.3)$ & $-0.2^{*}(1.3)$ & $0.2(1.2)$ \\
BMI SDS & $-0.1^{*}(1.51)$ & $0.4(1.3)$ & $-0.2^{*}(1.4)$ & $0.2(1.3)$ \\
WC SDS & $0.3^{*}(1.4)$ & $0.7(1.2)$ & $0.2^{*}(1.5)$ & $0.6(1.2)$ \\
BMI $\geq 95$ th centile $n(\%)$ & $106(16.3)$ & $108(18.0)$ & $104(11.4)$ & $78(14.7)$ \\
WC $\geq 95$ th centile $n(\%)$ & $124(19.0)$ & $122(20.7)$ & $153(16.8)$ & $109(20.5)$ \\
BMI $\geq 90$ th centile $n(\%)$ & $140(21.5)$ & $140(23.8)$ & $155(17.0)$ & $112(21.1)$ \\
WC $\geq 90^{\text {th }}$ centile $n(\%)$ & $159(24.4)$ & $170(29)$ & $223(24.5)$ & $143(26.9)$
\end{tabular}

SDS = standard deviation scores (generated from UK90 LMSgrowth (19) British WC (25) reference data); UK South Asian \& UK white boys and girls significantly different at ${ }^{*} \mathrm{P}<0.001$ level.

UK South Asian (of Indian, Pakistani, and Bangladeshi descent) and UK white data set collected in 2004-2007 (29); BMI = body mass index; $W C=$ waist circumference; $95^{\text {th }}$ percentile $=S D S>1.64 ; 90^{\text {th }}$ percentile $=S D S \geq 1.29$ 